\title{
Crystal structure of a minimal elF4E-Cup complex reveals a general mechanism of eIF4E regulation in translational repression
}

\author{
KERSTIN KINKELIN, ${ }^{1}$ KATHARINA VEITH, MARLENE GRÜNWALD, and FULVIA BONO ${ }^{2}$ \\ Max-Planck-Institute for Developmental Biology, 71076 Tübingen, Germany
}

\begin{abstract}
Cup is an elF4E-binding protein (4E-BP) that plays a central role in translational regulation of localized mRNAs during early Drosophila development. In particular, Cup is required for repressing translation of the maternally contributed oskar, nanos, and gurken mRNAs, all of which are essential for embryonic body axis determination. Here, we present the $2.8 \AA$ resolution crystal structure of a minimal elF4E-Cup assembly, consisting of the interacting regions of the two proteins. In the structure, two separate segments of Cup contact two orthogonal faces of elF4E. The elF4E-binding consensus motif of Cup (YXXXXLФ) binds the convex side of eIF4E similarly to the consensus of other eIF4E-binding proteins, such as 4E-BPs and eIF4G. The second, noncanonical, eIF4E-binding site of Cup binds laterally and perpendicularly to the elF4E $\beta$-sheet. Mutations of Cup at this binding site were shown to reduce binding to elF4E and to promote the destabilization of the associated mRNA. Comparison with the binding mode of eIF4G to eIF4E suggests that Cup and eIF4G binding would be mutually exclusive at both binding sites. This shows how a common molecular surface of eIF4E might recognize different proteins acting at different times in the same pathway. The structure provides insight into the mechanism by which Cup disrupts eIF4E-eIF4G interaction and has broader implications for understanding the role of $4 \mathrm{E}-\mathrm{BPs}$ in translational regulation.
\end{abstract}

Keywords: elF4E; Cup; 4E-BP; mRNA localization; translation

\section{INTRODUCTION}

mRNA localization and regulated translation control a wide range of cellular processes in eukaryotes. During mRNA transport, premature translation has to be suppressed, and inhibition is relieved only at the correct subcellular location (for review, see Vardy and Orr-Weaver 2007; Besse and Ephrussi 2008). Therefore, proteins acting as translational repressors are often part of the mRNA localization complexes that can assemble into large silencing particles. Frequently, translational repression occurs at the initiation step of translation, where, in the case of $5^{\prime}$ capped mRNAs, the translation initiation factor eIF4E binds to the $\mathrm{m}^{7} \mathrm{GTP}$ cap structure $\left(\mathrm{m}^{7} \mathrm{GpppN}\right.$, where $\mathrm{m}^{7} \mathrm{G}$ is 7-methylguanosine and $\mathrm{N}$ is the first nucleotide of the mRNA) to assemble the cap binding complex (for review, see Gebauer and Hentze

\footnotetext{
${ }^{1}$ Present address: Department of Biochemistry, Gene Center Munich, Ludwig-Maximilians-Universität München, 81377 Munich, Germany

${ }^{2}$ Corresponding author

E-mail fulvia.bono@tuebingen.mpg.de

Article published online ahead of print. Article and publication date are at http://www.rnajournal.org/cgi/doi/10.1261/rna.033639.112.
}

2004; Sonenberg and Hinnebusch 2009; Jackson et al. 2010). A critical step in this assembly process is the binding of the protein eIF4G to eIF4E. eIF4G is required to recruit the $43 \mathrm{~S}$ pre-initiation complex to the mRNA, and it provides a link, via the binding to the cytoplasmic poly(A)binding protein (PABPC), between the $5^{\prime}$ and the $3^{\prime}$ ends of the mRNA (for review, see Jackson et al. 2010).

The eIF4E-eIF4G association is targeted by a family of conserved eIF4E-binding proteins (4E-BPs) that negatively regulate translation by competing with eIF4G for eIF4E binding. This association is reversible and is regulated by phosphorylation (Lin et al. 1994; Pause et al. 1994). Phosphorylation of 4E-BP molecules releases $4 \mathrm{E}-\mathrm{BPs}$ from eIF4E, allowing an interaction with eIF4G and the reactivation of translation. In contrast, non- or hypophosphorylated forms of 4E-BPs have high affinity for eIF4E and repress translation (Haghighat et al. 1995; Mader et al. 1995; Gingras et al. 1999; Marcotrigiano et al. 1999; Gebauer and Hentze 2004). 4E-BPs act as global regulators of protein synthesis, with more pronounced effects on mRNAs with high secondary structure content in the $5^{\prime}$ untranslated regions (for review, see Topisirovic et al. 2011). 
The eIF4E-eIF4G interaction is also targeted to promote transcript-specific translational control. This role is best studied in Drosophila development, where several mRNAs that specify the body axes in the early embryo are localized to specific subcellular regions. In these cases, expression is tightly coordinated with mRNA localization to ensure the correct spatio-temporal activity of the localized factors during development.

One protein that targets specific localized transcripts in Drosophila is Cup. Cup binds to eIF4E and to RNA-binding proteins that specifically recognize regions at the $3^{\prime}$ UTRs of mRNAs. Cup is involved in repressing at least three localized and developmentally essential mRNAs in Drosophila-oskar, nanos, and gurken — and might function as a general repressor for many as-yet-unknown mRNAs (Schüpbach and Wieschaus 1991; Keyes and Spradling 1997; Verrotti and Wharton 2000; Wilhelm et al. 2003; Nakamura et al. 2004; Nelson et al. 2004; Zappavigna et al. 2004; Clouse et al. 2008). According to the current model, Cup is recruited to the $3^{\prime}$ UTRs of mRNA targets via different adaptor/repressor proteins that bind specifically to sequence/structure elements on the RNA. Cup then competes with eIF4G for binding to the cap-binding protein eIF4E and impairs the formation of the translation preinitiation complex. In the case of oskar and gurken mRNAs, Cup is recruited to the mRNA through binding to eIF4E and to Bruno (or Aret), which binds at the oskar 3' UTR (Kim-Ha et al. 1995; Webster et al. 1997; Norvell et al. 1999; Filardo and Ephrussi 2003; Nakamura et al. 2004). In the case of nanos mRNA, Cup is recruited by the protein Smaug (Nelson et al. 2004).

eIF4E is conserved in eukaryotes and consists of an $\mathrm{N}$-terminal unstructured extension and a globular domain that binds the $\mathrm{m}^{7} \mathrm{G}$ cap structure. Detailed structural information is available on eIF4E from different species, in complex with cap analogs and with peptides derived from eIF4G and $4 \mathrm{E}-\mathrm{BPs}$. These peptides bind in a similar mode to a conserved surface on eIF4E, opposite and distal to the $\mathrm{m}^{7} \mathrm{G}$ cap-binding pocket (Marcotrigiano et al. 1997, 1999; Matsuo et al. 1997; Niedzwiecka et al. 2002a; Gross et al. 2003; Tomoo et al. 2005; Volpon et al. 2006, 2010; Brown et al. 2007, 2009; Monzingo et al. 2007; Rosettani et al. 2007; Ashby et al. 2011; Liu et al. 2011; Siddiqui et al. 2012) (pdb id.: 3AM7).

Cup is an insect-specific protein of calculated weight $125.7 \mathrm{kDa}$ with no predictable folded domain and no structural information available at present. In the $\mathrm{N}$-terminal region, Cup contains a canonical eIF4E-binding motif (YXXXXL $\Phi$, where $\mathrm{X}$ is any residue and $\Phi$ is hydrophobic) followed by an eIF4E-transporter-like (4E-T-like) region (Haghighat et al. 1995; Mader et al. 1995; Wilhelm et al. 2003; Nakamura et al. 2004; Nelson et al. 2004). The consensus eIF4E-binding motif is shared by nonhomologous eIF4E-binding proteins such as eIF4G, 4E-BPs, 4E-T, and Bicoid (Mader et al. 1995; Dostie et al. 2000; Niessing et al.
2002). This motif is sufficient for the interaction with eIF4E and is predicted to bind in a similar fashion. C-terminal to the eIF4E-binding motif of Cup, between the canonical $4 \mathrm{E}-$ binding motif and the 4E-T-like region, a second loweraffinity, noncanonical binding region has been mapped by coprecipitation assays. This motif is sufficient to compete with eIF4G for eIF4E binding (Nelson et al. 2004).

Cup mutant Drosophila oocytes that lack the canonical binding site show premature oskar translation, indicating that the interaction between eIF4E and Cup is critical for the translational repression of oskar (Nakamura et al. 2004). However, recent studies in Drosophila cells have shown that, although the repression function of Cup resides at least partly in the consensus eIF4E-binding motif, the noncanonical binding region is responsible for the stabilization of the transcript by preventing decapping (Igreja and Izaurralde 2011).

We focused on the Cup-eIF4E interaction to get insights into the molecular mechanisms of translational repression and derepression that are still not well understood. In particular, we set out to understand how the noncanonical binding site of Cup interacts with eIF4E.

\section{RESULTS AND DISCUSSION}

\section{Structure determination and quality}

We could not purify full-length or truncated versions of isolated Cup due to poor expression and rapid degradation during purification. Therefore, the Drosophila (Dm) eIF4ECup core complex was reconstituted after coexpression of the two proteins in Escherichia coli, combining full-length eIF4E with Cup fragment 296-425 (Fig. 1). This region was chosen based on a combination of sequence conservation, secondary structure prediction, and prior knowledge on the interaction from the literature (Nelson et al. 2004). Throughout this study, we refer to Cup 296-425 simply as "Cup" unless otherwise specified. The purification led to a homogeneous eIF4E-Cup sample that did not crystallize. The binary complex was subjected to limited proteolysis using Glu-C, followed by anion exchange and size exclusion chromatography to separate the complex-containing fractions for crystallization experiments (Supplemental Fig. S1). Although the complex obtained was not fully homogeneous, crystals from this sample preparation grew in a hexagonal space group with two molecules per asymmetric unit and diffracted to $2.8 \AA$.

The structure was solved by molecular replacement using the human eIF4E coordinates (pdb id.: 3U7X) (Siddiqui et al. 2012) as a search model and refined to an $R_{\text {free }}$ of $24.4 \%, R_{\text {factor }}$ of $22.8 \%$, and good stereochemistry (Fig. 2; Table 1). The refined model consists of eIF4E residues 66-248 and two segments of Cup comprising residues 318-339 (canonical eIF4E-binding site I, 4E-BS I) and 362-376 (eIF4E-binding site II, 4E-BS II) (Fig. 2A,B). 
A

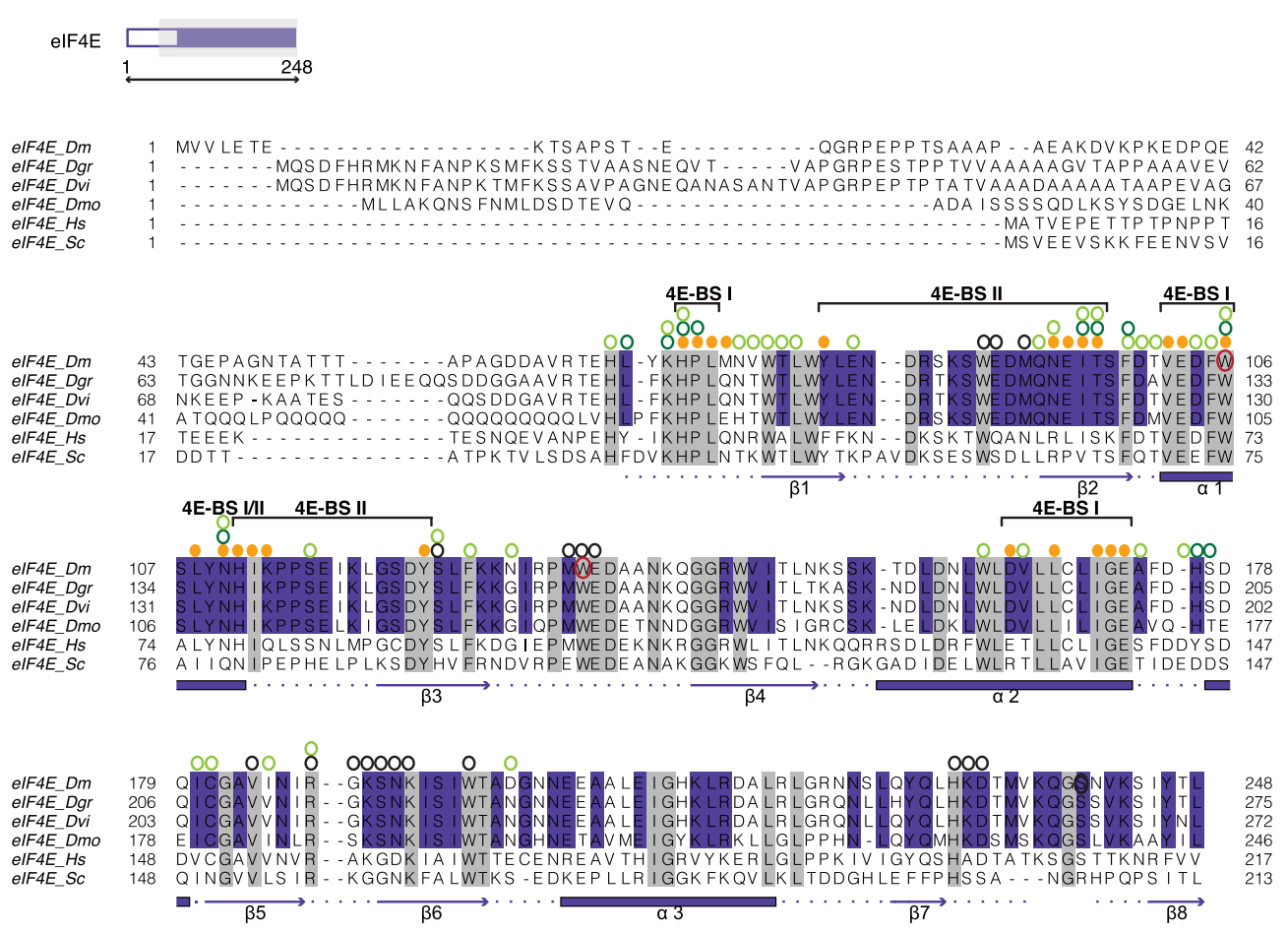

B

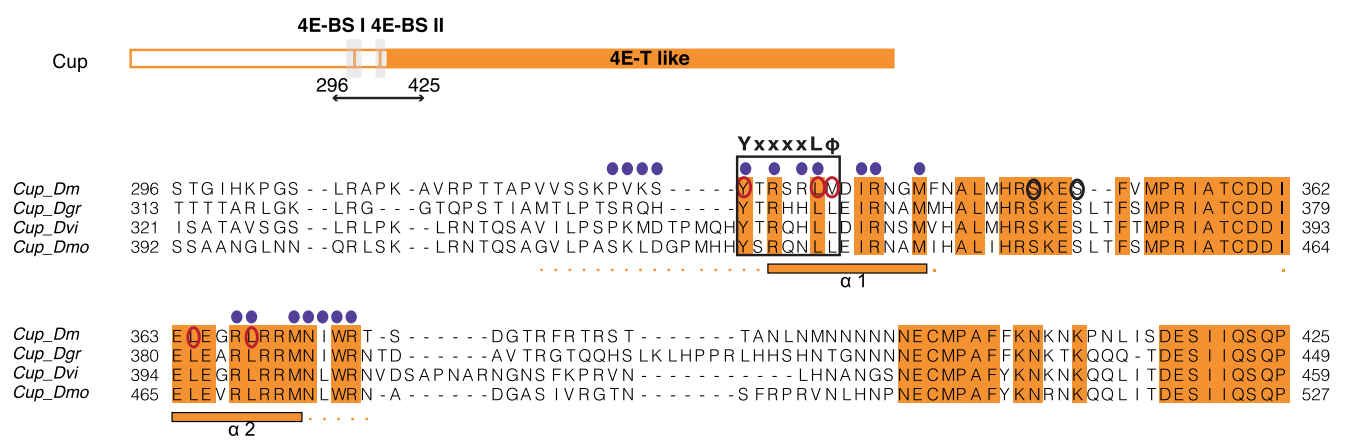

FIGURE 1. Sequence conservation and interactions in the eIF4E-Cup complex. Structure-based sequence alignment. Above each alignment is a schematic representation of the architecture of the proteins used in this study. Color-filled areas in the scheme identify structural and similarity domains, which include the eIF4E core (purple-blue) and the 4E-T-like region (orange). Indicated are the residue numbers corresponding to the constructs used for the complex reconstitution. (Gray) The portions of the polypeptides ordered in the three-dimensional (3D) structure. The secondary structure elements of Dm eIF4E and Cup are shown below the sequences as rectangles ( $\alpha$-helices) and arrows ( $\beta$-strands) with the same color code. Dotted lines represent extended/loop regions. Above the sequences, colored circles highlight the residues involved in the interaction with Cup (orange), and eIF4E (purple-blue) as identified using the AquaProt server (Reichmann et al. 2007). Other interactions known from previous structural studies are indicated as colored empty circles above the sequences: interactions with eIF4G (dark green), $\mathrm{m}^{7} \mathrm{GTP}$ (black), and 4E-BP (light green) (Marcotrigiano et al. 1997, 1999; Matsuo et al. 1997; Gross et al. 2003). Residues shown by mutagenesis to affect Cup-eIF4E interactions (Nakamura et al. 2004; Nelson et al. 2004) or that are phosphorylated (Zhai et al. 2008) are surrounded by a red or black circle, respectively. Regions of interaction with Cup binding site I or II are labeled as 4E-BS I and 4E-BS I, respectively. (A) The eIF4E alignment includes orthologs from Drosophila melanogaster (Dm), Drosophila grimshawi (Dgr), Drosophila virilis (Dvi), Drosophila mojavensis (Dmo), Saccharomyces cerevisiae (Sc), and Homo sapiens (Hs) (shown) and also from Xenopus laevis, Danio rerio, Caenorhabditis elegans, Arabidopsis. thaliana, and seven more insect species (data not shown). Conserved sequences shared by all eIF4E proteins are highlighted in gray, whereas residues conserved specifically in insects are highlighted in purple-blue. $(B)$ Cup alignment of the eIF4E interacting region including only the sequences of the orthologous proteins in insects used in A. Conserved residues are marked in orange. The eIF4E binding motif is boxed in black and labeled.

Other portions of the proteins are not present in the structure and are either poorly ordered or were removed during proteolysis. The two independent copies of the complex present in the asymmetric unit are very similar and superimpose with a root mean square deviation (RMSD) value of $0.472 \AA$ over $181 \mathrm{C}_{\alpha}$ atoms. Here we describe 


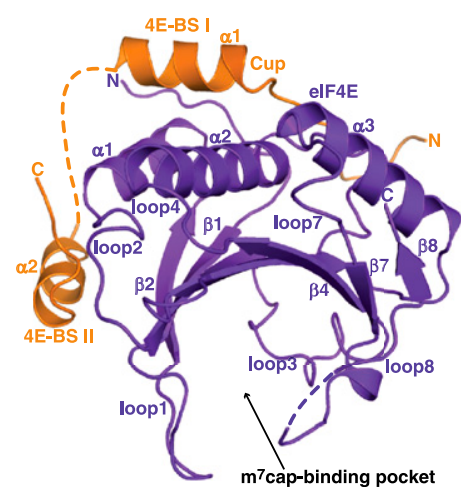

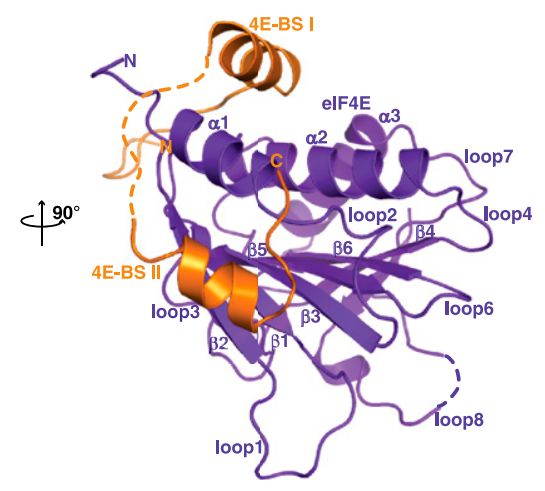

FIGURE 2. Structure of the eIF4E-Cup complex. (A) Cartoon view of the complex; eIF4E (purple-blue); Cup (orange). Secondary structure elements are labeled. (B) Cartoon view rotated $90^{\circ}$ around the $y$-axis. The eIF4E binding sites of Cup are labeled 4E-BS I and 4E-BS II. Disordered unmodeled stretches are represented as a dashed line for clarity. These and all other protein structure figures were generated using PyMOL (http://www.pymol.org).

complex 1 since complex 2 is engaged in lattice contacts at the binding surface for 4E-BS II, and there the Cup peptide is missing. In addition, localized differences in side-chain orientations at this region might be due to crystal packing.

\section{Overall structure of the complex}

Upon Cup binding, the overall structure of eIF4E remains essentially unchanged from the core of the protein previously described (Marcotrigiano et al. 1997, 1999; Matsuo et al. 1997; Niedzwiecka et al. 2002b; Gross et al. 2003; Tomoo et al. 2005; Volpon et al. 2006, 2010; Monzingo et al. 2007; Rosettani et al. 2007; Brown et al. 2009; Ashby et al. 2011; Liu et al. 2011; Siddiqui et al. 2012).

Briefly, eIF4E has a spherical body with a cavity that forms the $\mathrm{m}^{7} \mathrm{G}$ cap-binding site. The roof of the cavity is formed by a curved eight-stranded antiparallel $\beta$-sheet overlaid by three $\alpha$-helices. The helices form the convex region of the molecule on one side, whereas the $\beta$-sheet tops the $\mathrm{m}^{7} \mathrm{G}$ cap-binding cavity on the molecule's concave surface, on the other side. The $\mathrm{m}^{7} \mathrm{G}$ cap-binding pocket, empty in the structure, is delimited on the lateral sides by loop regions. These loop regions are only partially folded and ordered (Fig. 2). This is consistent with previous observations that they acquire secondary structure features upon $\mathrm{m}^{7} \mathrm{G}$ cap binding (McCubbin et al. 1988; McGuire et al. 1998; von der Haar et al. 2000; Cohen et al. 2001; Tomoo et al. 2003; Volpon et al. 2006).

Dm eIF4E superimposes with an RMSD between 0.671 and $1.348 \AA$ (more than $178 \mathrm{C}_{\alpha}$ atoms) on available structures of eIF4E proteins crystallized without the substrate (Volpon et al. 2006; Monzingo et al. 2007; Rosettani et al. 2007; Siddiqui et al. 2012) (human pdb id: 3TF2, 3U7X, 2JGC; wheat pdb id: 2IDR). Conformational variability can be detected when comparing Dm eIF4E with eIF4E in these structures mainly in the loop regions that compact upon $\mathrm{m}^{7} \mathrm{G}$ cap binding, such as loop1 (between $\beta 1$ and $\beta 2$ ), loop3 (between $\beta 3$ and $\beta 4$ ), and loop8 (between $\beta 7$ and $\beta 8$ ) (Fig. 2). Moreover, loop4 (connecting $\beta 4$ and $\alpha 2$ ), loop6 (between $\beta 5$ and $\beta 6$ ), and loop7 (between $\alpha 3$ and $\beta 7$ ) of eIF4E are displaced.

The important residues for $m^{7} \mathrm{G}$ cap binding have been defined by previous crystal structures (Marcotrigiano et al. 1997; Matsuo et al. 1997; Niedzwiecka et al. 2002b; Tomoo et al. 2003; von der Haar et al. 2004; for review, see Curry et al. 2009). Two tryptophan residues (corresponding to residues 89 and 135 in Dm eIF4E) impart the specificity for $m^{7} G$ cap recognition by sandwiching the $\mathrm{m}^{7} \mathrm{G}$ moiety with $\pi-\pi$ stacking interactions. The methyl group at N7 interacts with an acidic residue (Glu136 in Dm eIF4E), while the phosphate groups increase the overall affinity of the cap structure for eIF4E (for review, see von der Haar et al. 2004). In our eIF4E structure, the $\mathrm{m}^{7} \mathrm{G}$ cap-binding pocket is accessible and exposed to solvent.

Cup interacts with eIF4E as two short $\alpha$-helices connected by a linker that is disordered in the structure. Both

TABLE 1. Crystallographic statistics

\begin{tabular}{lc}
\hline Data collection & elF4E-Cup \\
Data set & SLS PXII \\
Beamline & P6 ${ }_{1} 22$ \\
Space group & $a=b=142.6, c=108.0$ \\
Unit cell $(\AA)$ & $\alpha=\beta=90^{\circ}, \gamma=120^{\circ}$ \\
& 1.0718 \\
Wavelength $(\AA)$ & $100-2.8(2.9-2.8)$ \\
Resolution range $(\AA)^{\mathrm{a}}$ & 16,494 \\
Unique reflections & 13.4 \\
Multiplicity & $99.9(99.9)$ \\
Completeness $(\%)^{\mathrm{a}}$ & $14.23(2.79)$ \\
$l / \sigma(\iota)^{\mathrm{a}}$ & $13.3(114.6)$ \\
$R_{\text {sym }}(\%)^{\mathrm{a}}$ & \\
Refinement & \\
Resolution range $(\AA)^{\mathrm{a}}$ & $80-2.80$ \\
$R_{\text {free }}(\%)^{\mathrm{a}}$ & 24.42 \\
$R_{\text {work }}(\%)^{\mathrm{a}}$ & 22.82 \\
RMSD bond $(\AA)$ & 0.003 \\
RMSD angle $\left({ }^{\circ}\right)$ & 0.653 \\
Bfactor protein $\left(\AA^{2}\right)$ & 80.04 \\
& \\
Ramachandran values & \\
Favored $(\%)$ & $97.4 \%($ outliers $0.0 \%)$ \\
Allowed $(\%)$ & $100 \%$ \\
\hline
\end{tabular}

Data collection and refinement statistics of the crystal structure of the minimal elF4E-Cup complex.

${ }^{a}$ Values in parentheses correspond to the highest-resolution shell.

${ }^{\mathrm{b}}$ Molprobity; http://molprobity.biochem.duke.edu/. 
helices extend into stretches without defined secondary structure elements at the $\mathrm{N}$ and $\mathrm{C}$ termini (Fig. 2). The two stretches, of 35 residues in total, bury $\sim 1.2 \%\left(350 \AA^{2}\right)$ of the solvent-accessible surface area of the eIF4E. The N-terminal segment of Cup that is visible in the electron density map includes the eIF4E consensus motif and docks at the convex surface of eIF4E, where it contacts part of the unstructured $\mathrm{N}$ terminus of the protein. This region of eIF4E had been previously identified by biochemical and structural studies as the functionally important region that is required to bind eIF4G and the 4E-PBs (mainly the helix $\alpha 2$ and the N-terminal portion of eIF4E) (Fig. 1; Matsuo et al. 1997; Marcotrigiano et al. 1999; Gross et al. 2003; Tomoo et al. 2005; Rosettani et al. 2007; Brown et al. 2009; Siddiqui et al. 2012) (pdb id. 3AM7). After a disordered linker of about 20 residues, Cup extends laterally on eIF4E, where a few, mainly hydrophobic, interactions create a specific binding surface distinct from the $4 \mathrm{E}$-consensus binding site. This second helix of Cup binds in an antiparallel fashion to the outermost $\beta$-strand on the side of eIF4E and continues with a short $\beta$-turn that extends back toward the convex surface of the protein. Both binding sites of Cup are situated away from the $m^{7} G$ capbinding pocket.

\section{Structure of the canonical binding site of Cup, binding site I}

The binding site I of Cup docks at the convex dorsal surface of eIF4E similarly to the previously described eIF4G and 4E-BPs peptides (Marcotrigiano et al. 1999; Gross et al. 2003; Tomoo et al. 2005; Rosettani et al. 2007; Brown et al. 2009; Siddiqui et al. 2012) (pdb id. 3AM7). Consensus residues (common to $4 \mathrm{G}$ and $4 \mathrm{E}-\mathrm{BP}$ ) make similar contacts with several invariant eIF4E side chains found in the helices $\alpha 1$ and $\alpha 2$ and also with the N-terminal extension of eIF4E. The first residue of the consensus motif, Tyr327 $7_{\text {Cup }}$, is located at the extended chain portion of the peptide $\mathrm{N}$-terminal of helix $\alpha 1$ (Fig. 3A,C). The next residues defined by the consensus, Leu332 $\mathrm{Cup}$ and Met333 Cup ( $\phi$ in the consensus motif), are at the first turn of the helix $\alpha 1$ (Fig. 3A). Tyr327 ${ }_{\text {Cup }}$ makes several contacts with the extended $\mathrm{N}$ terminus of eIF4E, involving the conserved $\mathrm{His}_{4 \mathrm{E}}, \mathrm{Pro}_{4 \mathrm{E}}$, and Leu72 $4 \mathrm{E}$. In particular, the hydroxyl group of the side chain forms a hydrogen bond with the carbonyl backbone of Pro71 $4 \mathrm{E}$. Tyr327 Cup is in van der Waals contact with Val102 $4 \mathrm{E}$ on helix $\alpha 1$ of eIF4E and hydrogenbonds with the main chain at the tip of helix $\alpha 2$ of eIF4E (Fig. 3C). Leu332 Cup serves as another important anchor to the dorsal surface of eIF4E, interacting with $\operatorname{Trp}_{106} 6_{4 \mathrm{E}}$ and Val102 ${ }_{4 \mathrm{E}}$ on helix $\alpha 1$ and with Leu $167_{4 \mathrm{E}}$ on helix $\alpha 1$ (Fig. $3 \mathrm{~A})$. Mutations at $\operatorname{Trp} 106_{4 \mathrm{E}}$ have been shown to disrupt the interaction between Cup and eIF4G in vitro (Fig. 3A; Nakamura et al. 2004; Nelson et al. 2004).

At the back of the helix, Ile $335_{\text {Cup }}$ contacts His $70_{4 \mathrm{E}}$ on the N-terminal tail of eIF4E and Val102 $4 \mathrm{E}$ and Glu $103_{4 \mathrm{E}}$ on helix $\alpha 1$ of eIF4E (Fig. 3C). At the front side, two arginine residues, Arg329 ${ }_{\text {Cup }}$ and Arg336 Cup, reach out from helix $\alpha 1$ of Cup to stabilize the eIF4E-Cup interaction. In particular, Arg329 ${ }_{\text {Cup }}$ makes a salt bridge with Asp164 $4 \mathrm{E}$ and contacts Leu167 $4 \mathrm{E}$, both of which are on helix $\alpha 2$ of eIF4E. Arg336 $6_{\text {Cup }}$ shields the hydrophobic surface of $\operatorname{Trp} 106_{4 \mathrm{E}}$ and
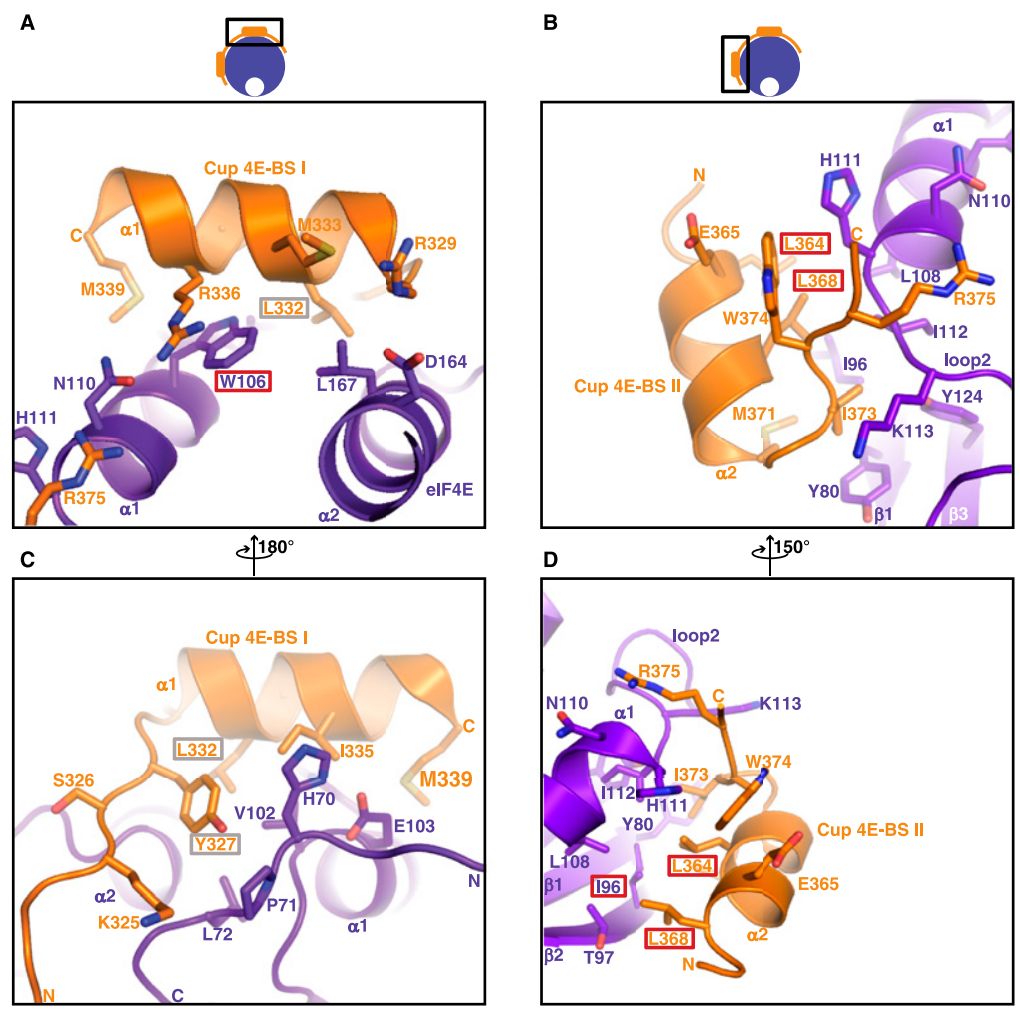

FIGURE 3. Details of the interactions between eIF4E and Cup. Close-up views of the interactions between eIF4E and Cup. (On top) Schematic drawings of the complex with the zoomed regions boxed in black. Interacting residues on eIF4E (purple-blue); interacting side chains on Cup (orange). Secondary structure elements of eIF4E and Cup are labeled. Residues of Cup or eIF4E mutated in this study are highlighted with a red box or with a gray box if part of the $4 \mathrm{E}$ binding consensus motif. $(A)$ This view shows the interaction between helices $\alpha 1$ and $\alpha 2$ of eIF4E and the helix $\alpha 1$ of Cup, centered at $\operatorname{Trp} 106_{4 \mathrm{E}}(4 \mathrm{E}-\mathrm{BS} \mathrm{I})$. The molecules are viewed in a similar orientation to that used in Figure 2A. (B) Interactions at Cup binding site II (4E-BS II) showing the prominent interaction of $\operatorname{Trp} 374_{\mathrm{Cup}}$. Strands $\beta 1$ and $\beta 3$, helix $\alpha 1$, and loop 2 of eIF4E and the helix $\alpha 2$ and $\beta$ turn of Cup are shown. The molecules are viewed in a similar orientation to that used in Figure 2B. (C) Interactions at Cup 4E-BS I. Cartoon view rotated $180^{\circ}$ around the $y$-axis as compared with $A$. (D) Interactions at Cup 4E-BS II. Cartoon view rotated $150^{\circ}$ around the $y$-axis as compared with $B$. 
hydrogen-bonds with Asn $110_{4 \mathrm{E}}$ on $\alpha 1$ of eIF4E (Fig. 3A,C). The last visible residue of this binding site is Met339 ${ }_{\text {Cup }}$ at the very C terminus of helix $\alpha 1$ of Cup (Fig. 3A). Deletion of this region up to the last residue of 4E-BS I consensus Met $333_{\text {Cup }}$ shows ectopic expression of oskar in mutant Dm oocytes (Nakamura et al. 2004). In addition to the conserved interactions described, nonconserved residues at the extended N-terminal portion of Cup also contribute to the binding. For example, Lys $325_{\text {Cup }}$ and Ser $326_{\text {Cup }}$ contact conserved residues at the very $\mathrm{N}$-terminal portion of eIF4E and at the tip of helix $\alpha 2$ of eIF4E (Fig. 3C).

\section{Structure of Cup binding site II: The noncanonical eIF4E-binding site}

Binding site II of Cup docks laterally with a helix $(\alpha 2)$ that lies antiparallel to the outer $\beta$-strand $(\beta 2)$ of eIF4E and a turn that points upward toward the convex surface of eIF4E (Fig. 3B). This binding site has rather few conserved contacts that are nevertheless sufficient to stabilize the interaction (Fig. 3B,C; Supplemental Fig. S2). On helix $\alpha 2$ of Cup, conserved Leu364 3 Cup points toward Leu108 ${ }_{4 \mathrm{E}}$ on helix $\alpha 1$ of eIF4E and is in contact with Thr97 $4 \mathrm{E}$ and Ile96 $6_{4 \mathrm{E}}$ at the strand $\beta 2$ of eIF4E (Fig. 3C). Ile96 $4 \mathrm{E}$, a conserved residue, is central in the interaction with Cup 4E-BS II and provides a hydrophobic core around which conserved hydrophobic residues from Cup are arranged (Fig. 3B,C; Supplemental Fig. S2). Ile $96_{4 \mathrm{E}}$ is also contacted by the side chains of Arg367 Cup (nonvisible in Fig. 3C) and Met371 $1_{\text {Cup. }}$. The latter, at the C-terminal end of Cup helix $\alpha 2$, also contacts Tyr80 $4 \mathrm{E}$ and Asn94 $4 \mathrm{E}$ (nonvisible in Fig. 3B) on the $\beta 1$ and $\beta 2$ strands of eIF4E, respectively. Moreover, conserved Leu368 ${ }_{\text {Cup }}$ makes side-chain contacts with Ile96 ${ }_{4 \mathrm{E}}$ as well as with invariant Ile112 $4 \mathrm{E}$. Leu368 $\mathrm{Cup}$ and Leu364 ${ }_{\text {Cup }}$ have been previously shown to reduce binding to eIF4E when mutated (Nelson et al. 2004; Igreja and Izaurralde 2011). Mutations at these residues have functional relevance in cell-based assays, reducing eIF4E-bound mRNA stability (Igreja and Izaurralde 2011). Interestingly, the residues corresponding to Ile964 $4 \mathrm{E}$ and to $\mathrm{Thr} 97_{4 \mathrm{E}}$ have also been shown to be involved in binding both eIF4G and 4E-BPs in yeast (Fig. 1; Matsuo et al. 1997; Gross et al. 2003).

On the $\beta$-turn, Ile $373_{\text {Cup }}$ contacts Tyr $80_{4 \mathrm{E}}$ and $\mathrm{Ile} 96_{4 \mathrm{E}}$ on the $\beta$-strands $\beta 2$ and $\beta 1$ of eIF4E and on loop 2 of eIF4E, Ile112 ${ }_{4 \mathrm{E}}$, and, through a main-chain hydrogen bond, Lys $113_{4 \mathrm{E}}$. Ile $373_{\text {Cup }}$ also makes a contact with Tyr124 on $\beta 3$, linking the core of the protein to Cup 4E-BS II (Fig. 3B). A tryptophan residue on the $\beta$-turn, Trp374 Cup, is sandwiched between His $111_{4 \mathrm{E}}$ on one side with a stacking interaction and Glu365 Cup displaying both a structural function by fixing the angle of Cup helix $\alpha 2$ with the turn and a docking point on eIF4E. At the $\mathrm{C}$ terminus, Arg $375_{\text {Cup }}$ stretches toward $4 \mathrm{E}-\mathrm{BS}$ I and contacts N110 $4 \mathrm{E}$ and Lys $113_{4 \mathrm{E}}$.

\section{Conserved surfaces on $4 \mathrm{E}$ recognize different proteins}

Although most of the intermolecular contacts between eIF4E and Cup are conserved, some interactions involve residues that are uniquely conserved in insects (Fig. 4A). As described, the conserved hotspot on the convex top of eIF4E is the docking site of the consensus binding site of Cup and of other nonhomologous proteins that contain this motif. Conversely, the second binding site of Cup is not obviously identifiable from the primary sequence in other proteins. However, conservation on eIF4E at this lateral surface and its apparent hydrophobic nature raises the possibility that other eIF4E-binding proteins might dock at this second surface on eIF4E (Fig. 4A,B; Supplemental Fig. S3). In particular, comparison of the Dm eIF4E-Cup minimal complex with the solution structure of the yeast eIF4E-eIF4G complex, reconstituted with fulllength eIF4E and a fragment of eIF4G (Gross et al. 2003), suggests that steric incompatibility with eIF4G might extend to the 4E-BS II binding site. Although it is difficult to optimally superpose the two structures due to conformational flexibility, it appears that the interaction surface on eIF4E for eIF4G helix $\alpha 5$ and for Cup 4E-BS II helix $\alpha 2$ overlaps, at least partially, at the C-terminal and at the $\mathrm{N}$-terminal portion of the respective helices (Fig. 4B). This is consistent with the data that a Cup 4E-BS II peptide is sufficient to displace an eIF4G fragment (Nelson et al. 2004). Cup might therefore dock laterally to eIF4E with the lower-affinity 4E-BS II and then stabilize the interaction by the binding of the 4E-BS I canonical, high-affinity binding site. Interestingly, data from biochemical, biophysical, and NMR titration experiments point to the presence of interaction surfaces beyond the 4E-BS I docking site on eIF4E for both eIF4G and the 4E-BPs (Matsuo et al. 1997; Hershey et al. 1999; Gross et al. 2003; Mizuno et al. 2008; Paku et al. 2011). In particular, residues of eIF4E that show chemical shift changes in NMR titration with 4E-BP1 overlap with corresponding residues involved in binding Cup (Fig. 1A; Matsuo et al. 1997). This is consistent with the eIF4E-Cup and eIF4E-eIF4G superposition and suggests that the lateral binding site on eIF4E could be generally exploited by diverse eIF4E-binding proteins.

\section{Insights into Cup function from the structure}

During fly development, Cup functions in mRNA localization while simultaneously repressing translation. This repression is reversed once the mRNAs arrive at their target destination and, unlike other translational repression pathways, does not result in degradation. The Cup 4E-BS II binding site, although not sufficient for repression (Nakamura et al. 2004; Igreja and Izaurralde 2011), is responsible for the concomitant stabilization of reporter mRNAs in Dm 
A

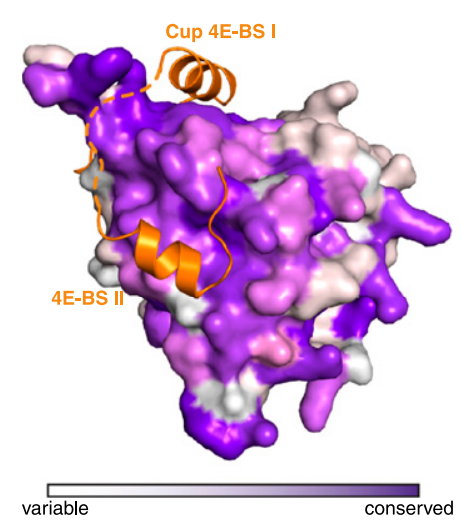

C
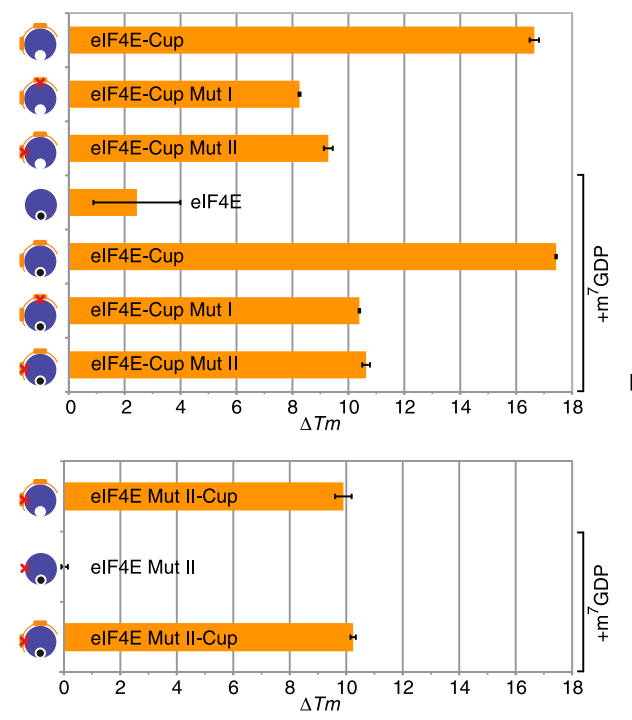

B

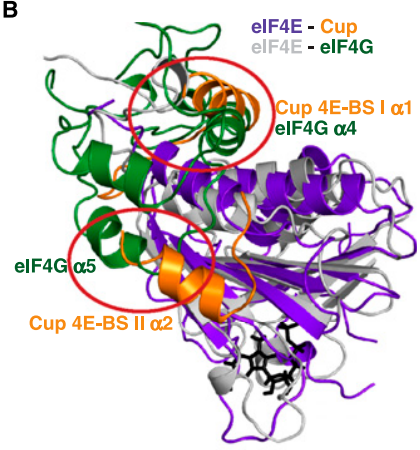

D

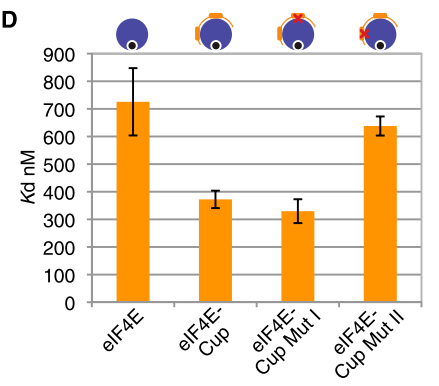

$E$

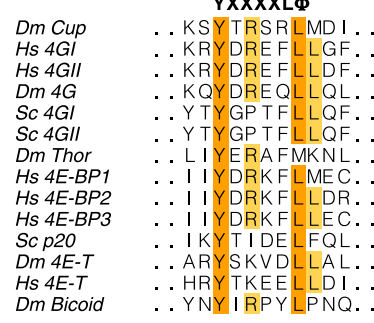

FIGURE 4. Protein recognition at similar molecular surfaces on eIF4E. The complex is shown in a similar view as in Figure 2B. $(A)$ eIF4E is rendered as a surface, with Cup as a cartoon in orange. The surface is colored according to conservation across insects (with a gradient from white to purple indicating increasingly conserved residues). (B) The lateral surface of eIF4E is used for binding both Cup and eIF4G. A cartoon representation of yeast eIF4E (gray) is shown bound to eIF4G (dark green) (pdb id. 1rf8) (Gross et al. 2003). The structures are shown after superimposition in a similar orientation as in Figure 2B. (C) DSF graph of protein stability. (Top) eIF4E-Cup, eIF4E-Cup-Mut I, or eIF4E-Cup-Mut II with or without $\mathrm{m}^{7} \mathrm{GDP}$ and eIF4E with $\mathrm{m}^{7} \mathrm{GDP}$. The bars show the mean melting temperature difference $\left(\Delta T_{\mathrm{m}}\right)$, and the error bars represent the standard deviation from three independent measurements. The measurements are normalized to the $T_{\mathrm{m}}$ measurement for unbound eIF4E. (Bottom) eIF4E Mut II-Cup with or without $\mathrm{m}^{7} \mathrm{GDP}$ and eIF4E Mut II with $\mathrm{m}^{7} \mathrm{GDP}$. The measurements are normalized to the $T_{\mathrm{m}}$ measurement for unbound eIF4E Mut II. (On the left) Schematics showing the complexes used; (red crosses) mutations. (D) ITC measurements of eIF4E, eIF4E-Cup, eIF4E-Cup-Mut I, or eIF4E-Cup-Mut II for $\mathrm{m}^{7} \mathrm{GDP}$ affinity. The bars represent the mean affinity (nanomolar), and the error bars show the standard deviation from three independent measurements (a typical ITC trace and curve are shown in Supplemental Fig. S4). (On top of the graph) Schematics of the complexes used in the measurements. (E) Sequence alignment of consensus eIF4E binding motifs from different 4E-BPs.

cells. We therefore asked whether Cup binding could exert a stabilizing activity on eIF4E in vitro that would explain how it protects the $5^{\prime}$ end of mRNAs from the action of decapping and degrading factors and/or enhance eIF4E binding affinity for the cap structure. We performed thermal

denaturation assays using differential scanning fluorimetry (DSF) (Niesen et al. 2007) of eIF4E unbound, eIF4ECup, eIF4E-Cup carrying Tyr342Ala Cup $_{1}$ and Leu347Ala ${ }_{\text {Cup }}$ mutations (Cup Mut I), and eIF4E-Cup carrying Leu364Ala ${ }_{\text {Cup }}$ and Leu368Ala ${ }_{\text {Cup }}$ mutations (Cup Mut II). Cup Mut I affects Cup 4E-BS I binding (Nakamura et al. 2004; Nelson et al. 2004; Igreja and Izaurralde 2011). Conversely, Cup Mut II mutations impair Cup 4E-BS II binding and promote RNA degradation in vivo while only reducing Cup binding to eIF4E (Nelson et al. 2004; Igreja and Izaurralde 2011). We also used an eIF4E Mut II-Cup complex where eIF4E carried a Ile96Arg mutation designed based on the structure to impair Cup binding at the $4 \mathrm{E}-\mathrm{BS}$ II surface. The use of the classical Trp106Ala mutant of eIF4E, that had been shown to disrupt Cup binding in Dm (Fig. 1; Nakamura et al. 2004; Nelson et al. 2004) was not possible since this mutant appear to be largely unfolded both in size exclusion chromatography (SEC) of the recombinant proteins and in 1D NMR experiments (Supplemental Fig. S5). Remarkably, the interactions of eIF4E with Cup mutants I or II are stable enough to allow copurification in SEC (Supplemental Fig. S5).

We show that Cup binding stabilizes eIF4E as indicated by the $16.6^{\circ} \mathrm{C}$ shift in apparent melting temperature $\left(\Delta T_{\mathrm{m}}\right)$ to a higher temperature as compared with unbound eIF4E. Interestingly, the complex with Cup Mut I has an apparent $\Delta T_{\mathrm{m}}$ of $8.2^{\circ} \mathrm{C}, 8.4^{\circ} \mathrm{C}$ less than the wildtype (wt) complex. Similarly, the complex with Cup Mut II has an apparent $\Delta T_{\mathrm{m}}$ of $9.3^{\circ} \mathrm{C}, 7.4^{\circ} \mathrm{C}$ less than the wt complex. Consistently, the reciprocal mutant on eIF4E at 4E-BS II, although less stable $\left(T_{\mathrm{m}}\right.$ of $34.7^{\circ} \mathrm{C}, 4^{\circ} \mathrm{C}$ lower than that of eIF4E wt), when in complex with Cup wt is stabilized as shown by a $\Delta T_{\mathrm{m}}$ of $9.9^{\circ} \mathrm{C}$ close to the shift observed for the $\Delta T_{\mathrm{m}}$ of the eIF4E-Cup Mut II complex. This suggests an additive effect of the two binding sites to the overall stability of eIF4E and indicates that the 4E-BS II binding site contributes significantly to eIF4E stabilization. Therefore, binding at this surface of eIF4E might play an important role in preventing the degradation of the mRNA. Addition of $\mathrm{m}^{7} \mathrm{GDP}$ increases stability further for all pro- 
teins/complexes, although its contribution appears to be less than the Cup binding contribution (Fig. 4C). Note that addition of the $\mathrm{m}^{7} \mathrm{G}$ cap structure does not result in stabilization for eIF4E Mut II, strongly suggesting that in this mutant, binding to the $\mathrm{m}^{7} \mathrm{G}$ cap structure is compromised. Similarly, eIF4G and 4E-BPs binding enhance eIF4E's affinity for the $\mathrm{m}^{7} \mathrm{G}$ cap (Marcotrigiano et al. 1999; Gross et al. 2003; Volpon et al. 2006; Brown et al. 2009; Yanagiya et al. 2009).

Since the eIF4E stabilization effect is similar for the two BS on Cup and does not explain their different function in vivo, we asked whether the affinity of eIF4E for $\mathrm{m}^{7} \mathrm{G}$ cap binding was altered in the complex with Cup Mut I or Cup Mut II as compared with the complex with Cup wt. Using Isothermal Titration Calorimetry (ITC), the affinity of $\mathrm{m}^{7} \mathrm{GDP}$ for eIF4E was measured to be $726 \pm 122 \mathrm{nM}$ (mean value from three independent measurements). This is in agreement with studies performed with human and yeast proteins that show an affinity in the nanomolar range (Niedzwiecka et al. 2002b; Scheper et al. 2002; for review, see Curry et al. 2009). The affinity of $\mathrm{m}^{7} \mathrm{GDP}$ for eIF4E as determined in a preformed, stoichiometric complex with Cup is $372 \pm 32 \mathrm{nM}$, almost twofold higher than that of the protein alone (Fig. 4D; Supplemental Fig. S4). Interestingly, the affinity of $\mathrm{m}^{7} \mathrm{GDP}$ for eIF4E in complex with Cup Mut II (the mutant that does not bind at 4E-BS II) is similar to that of eIF4E alone $(638 \pm 35 \mathrm{nM})$, suggesting that it is primarily the binding at the second binding site of Cup that regulates the $\mathrm{m}^{7} \mathrm{G}$ cap-structure binding properties of eIF4E. In support of this, the affinity of $\mathrm{m}^{7} \mathrm{GDP}$ for eIF4E in complex with Cup Mut I is similar to that of the eIF4E-Cup wt complex. This is also consistent with the idea that eIF4E regulatory proteins induce an allosteric effect on $\mathrm{m}^{7} \mathrm{G}$ cap binding. Moreover, it has previously been observed that occupation of the dorsal surface of eIF4E (by consensus peptides of eIF4G and 4EBPs) is not sufficient for this effect, whereas larger fragments, potentially including an additional binding site, are required for increased association of the $\mathrm{m}^{7} \mathrm{G}$ cap (Haghighat and Sonenberg 1997; Ptushkina et al. 1998, 1999; Hershey et al. 1999; von der Haar et al. 2000, 2006; Gross et al. 2003). As in the case of Cup, the conserved $\beta 1$ and $\beta 2$ strands of eIF4E are involved in the binding of nonconsensus portions of eIF4G and 4E-BPs (Matsuo et al. 1997; Gross et al. 2003).

\section{CONCLUSIONS}

Our results provide a structural basis for the mode of binding of Cup to eIF4E and rationalize previous biochemical studies that showed a second eIF4E-binding site on Cup. While the consensus binding site 4E-BS I binds as predicted at a conserved patch on the dorsal surface of eIF4E, the second binding site of Cup docks also at a conserved surface and partially overlaps with the binding site of yeast eIF4G. This explains why a peptide that encompasses 4E-BS II but lacking 4E-BS I is sufficient to compete with a fragment of eIF4G (Nelson et al. 2004). Therefore, eIF4E and eIF4G binding is mutually exclusive at both binding sites. Moreover, this interaction is not restricted to Cup; indeed, both eIF4G and $4 \mathrm{E}-\mathrm{BPs}$ have additional binding sites on eIF4E. Therefore, the presence of binding sites additional to the consensus is widespread in $4 \mathrm{E}$-binding proteins and could involve a shared surface at the edge of the $\beta$-sheet of eIF4E. Cup 4E-BS II, which binds with low affinity (Nelson et al. 2004), could perhaps dock laterally on eIF4E first followed by 4E-BS I that then displaces eIF4G and stabilizes the binding to the protein with high-affinity recognition.

In vitro, Cup binding alone is sufficient to increase the thermal stability of eIF4E. The affinity of eIF4E for the $\mathrm{m}^{7} \mathrm{G}$ cap structure is likewise increased in the presence of Cup. Therefore, the effect of Cup binding to eIF4E is twofold: On one hand, it stabilizes the eIF4E fold; and on the other, it maintains a strong grip of eIF4E on the mRNA in vitro. This is consistent with a role for Cup 4E-BS II in stabilizing the mRNA (by preventing decapping) and simultaneously blocking eIF4G recruitment. These findings also raise the possibility that the consensus motif is, in fact, responsible for the consolidation of the binding of $4 \mathrm{E}-\mathrm{BPs}$ to eIF4E and that a second, lateral binding site would initiate competition and strengthen the affinity for the mRNA at the same time.

How translation activation occurs after mRNA localization is still poorly understood and might involve phosphorylation. Phosphorylated peptides have been identified by proteomic studies at conserved Ser residues (Ser347 and Ser350) located in the linker between the two Cup binding sites (Fig. 1B; Zhai et al. 2008). Although these residues were disordered and were therefore not visible in the structure, one can imagine that phosphorylation at the juncture between the two Cup binding sites could impact on Cup binding. Whether phosphorylation is involved in regulating Cup function in translational repression needs to be investigated further.

\section{MATERIALS AND METHODS}

\section{Protein purification}

Drosophila (Dm) eIF4E full-length (wt or mutated) and Dm Cup (residues 296-425) (wt or mutated) were coexpressed in E. coli BL21-Gold (DE3) pLysS cells (Stratagene) as an N-terminal hexahistidine and a GST fusion, respectively. Cells were grown to an $\mathrm{OD}_{600}$ of 2.0 in autoinducing medium (Studier 2005) and induced for $12-15 \mathrm{~h}$ at $20^{\circ} \mathrm{C}$. Proteins were purified from cleared cell lysates by glutathione affinity chromatography in buffer A (20 mM Tris at pH 7.5, $100 \mathrm{mM} \mathrm{NaCl}, 1 \mathrm{mM}$ dithiothreitol [DTT]) with a gradient of $0-20 \mathrm{mM}$ reduced glutathione, followed by proteolytic removal of the affinity tags with the TEV protease during dialysis into buffer A. The complex was further purified 
by anion-exchange chromatography with a gradient of $0.1-1 \mathrm{M}$ $\mathrm{NaCl}$ to remove the GST tag.

Fractions containing the complex were pooled and concentrated to $0.5 \mathrm{mg} / \mathrm{mL}$. For limited proteolysis, the complex was incubated on ice for $50 \mathrm{~min}$ in presence of Glu-C (Roche) at a 1:25 $(\mathrm{w} / \mathrm{w})$ enzyme-to-protein ratio. The reaction was stopped with $5 \mathrm{mM}$ 4-(2-Aminoethyl)-benzenelsulfonyl fluoride hydrochloride (AEBSF, AppliChem). After a second pass over the anion exchange column as described above, the collected flowthrough was further purified by size exclusion chromatography (Superdex 200 16/60; GE Healthcare). The fractions containing the stable eIF4ECup core complex were pooled and concentrated.

Dm eIF4E unbound was expressed as an N-terminal hexahistidine fusion as above and purified from cleared cell lysates by hisselective Cobalt affinity chromatography in buffer A (20 mM Tris at $\mathrm{pH} 7.5,100 \mathrm{mM} \mathrm{NaCl}, 5 \mathrm{mM}$ imidazole) with a gradient of 5-250 mM imidazole, followed by proteolytic removal of the affinity tag with the TEV protease during dialysis into buffer B (20 $\mathrm{mM}$ Tris at $\mathrm{pH} 7.5,100 \mathrm{mM} \mathrm{NaCl}, 1 \mathrm{mM}$ dithiothreitol [DTT]). After a second pass over a $\mathrm{Ni}^{2+} \mathrm{NTA}$ column, the collected flowthrough was further purified as above.

\section{Crystallization}

Crystals of eIF4E-Cup were grown at $18^{\circ} \mathrm{C}$ by vapor diffusion from sitting drops, formed by equal volumes $(100+100 \mathrm{~nL})$ of complex and crystallization buffer (20\% PEG 3350, $200 \mathrm{mM}$ calcium acetate), suspended over a reservoir of $70 \mu \mathrm{L}$. Platelike crystals grew after several months to a size of $\sim 500 \times 80 \times$ $200 \mu \mathrm{m}$ and could not be reproduced. These crystals diffracted to $2.8 \AA$ resolution and contained two complexes per asymmetric unit. They belong to the hexagonal space group $P 6_{1} 22$ with cell dimensions $a=b=142.6 \AA, c=108 \AA, \alpha=\beta=90^{\circ}, \gamma=120^{\circ}$ with a solvent content of $61 \%$.

\section{Data collection and structure determination}

For data collection, crystals were stabilized in a solution consisting of the mother liquor supplemented with $30 \%$ glycerol as cryoprotectant and flash-cooled in liquid nitrogen. Crystallographic data were collected at the PXII beamline of the Swiss Light Source (SLS) (Villigen, Switzerland). Data were processed and scaled using XDS (Kabsch 1993). The structure was solved by molecular replacement using PHASER (McCoy et al. 2007). The search model included the eIF4E human structure ( $\mathrm{pdb}$ id: 3U7X). Refinement was performed using iterative cycles of model building in COOT (Emsley and Cowtan 2004) and restrained refinement in PHENIX 1.7.3 (Adams et al. 2010). The Ramachandran plot statistics in Table 1 were calculated with the program Molprobity (Chen et al. 2010).

\section{Differential scanning fluorimetry}

The thermal shift assays were performed as described (Niesen et al. 2007). For the assays, $9 \mu \mathrm{M}$ eIF4E, eIF4E-Cup, eIF4E-Cup Mut I, or eIF4E-Cup Mut II were used, with or without $\mathrm{m}^{7} \mathrm{GDP}$ (Sigma-Aldrich) in two different buffers (buffer1: HEPES at $\mathrm{pH}$ 7.4, $100 \mathrm{mM} \mathrm{KCl}$; buffer2 [data not shown]: Tris at $\mathrm{pH}$ 7.5, $100 \mathrm{mM} \mathrm{NaCl}$ ) and with $5 \times$ SYPRO Orange dye (Invitrogen). A temperature gradient from $20^{\circ} \mathrm{C}$ to $85^{\circ} \mathrm{C}$ was performed in stepwise increments of $20 \mathrm{sec}$ at $1^{\circ} \mathrm{C}$, followed by a 5-sec equilibration after each step. Control assays were performed with the buffers alone and with unbound eIF4E. To form the complex with $\mathrm{m}^{7} \mathrm{GDP}$, the substrate was mixed in a 1:1 ratio with the protein/complex. Data from three independent measurements were evaluated as in Niesen et al. (2007) using the Boltzmann equation to fit the fluorescent data and calculate the $T_{\mathrm{m}}$ of protein unfolding (GraphPad Prism software).

\section{ITC analysis}

ITC analysis was performed with a VP-ITC Micro-calorimeter (Microcal). The solution of eIF4E, eIF4E-Cup, eIF4E-Cup Mut I, or eIF4E-Cup Mut II $(20 \mu \mathrm{M})$ in the calorimetric cell was titrated with $\mathrm{m}^{7} \mathrm{GDP}(200 \mu \mathrm{M})$ dissolved in the same buffer (20 mM HEPES at $\mathrm{pH} 7.4,100 \mathrm{mM} \mathrm{KCl}$ ) in a titration cell at $20^{\circ} \mathrm{C}$. Each titration experiment consisted of a $4-\mu \mathrm{L}$ injection followed by 29 injections of $10 \mu \mathrm{L}$. The thermodynamic parameters were estimated using a one-site model using Origin (version 7.0). Measurements were performed in triplicate.

\section{DATA DEPOSITION}

The coordinates and structure factors have been deposited in the Macromolecular Structure Database of the European Bioinformatic Institute (EBI) with ID code 4axg.

\section{SUPPLEMENTAL MATERIAL}

Supplemental material is available for this article.

\section{ACKNOWLEDGMENTS}

We thank the staff at SLS for excellent assistance with data collection, and Jerome Basquin and the staff of the MPIMartinsried crystallization facility for crystallization screening. We thank Oliver Weichenrieder and Andreas Boland for help with data collection and Remco Sprangers for NMR recordings, Guido Sauer for Mass Spectrometry analysis, Yvonne Grömping and Silvia Würtemberger for assistance with ITC measurements, and Catia Igreja for the Cup mutant clones. We also thank Elisa Izaurralde, Atlanta Cook, and Daniela Lazzaretti for critical reading of the manuscript. This study was supported by the Max Planck Gesellschaft.

Received April 4, 2012; accepted June 4, 2012.

\section{REFERENCES}

Adams PD, Afonine PV, Bunkóczi G, Chen VB, Davis IW, Echols N, Headd JJ, Hung L-W, Kapral GJ, Grosse-Kunstleve RW, et al. 2010. PHENIX: A comprehensive Python-based system for macromolecular structure solution. Acta Crystallogr D Biol Crystallogr 66: $213-221$.

Ashby JA, Stevenson CEM, Jarvis GE, Lawson DM, Maule AJ. 2011. Structure-based mutational analysis of eIF4E in relation to $s b m 1$ resistance to pea seed-borne mosaic virus in pea. PLOS ONE 6: e15873. doi: 10.1371/journal.pone.0015873.

Besse F, Ephrussi A. 2008. Translational control of localized mRNAs: Restricting protein synthesis in space and time. Nat Rev Mol Cell Biol 9: 971-980. 
Brown CJ, McNae I, Fischer PM, Walkinshaw MD. 2007. Crystallographic and mass spectrometric characterisation of eIF4E with $\mathrm{N}^{7}$-alkylated cap derivatives. J Mol Biol 372: 7-15.

Brown CJ, Verma CS, Walkinshaw MD, Lane DP. 2009. Crystallization of eIF4E complexed with eIF4GI peptide and glycerol reveals distinct structural differences around the cap-binding site. Cell Cycle 8: 1905-1911.

Chen VB, Arendall WB, Headd JJ, Keedy DA, Immormino RM, Kapral GJ, Murray LW, Richardson JS, Richardson DC. 2010. MolProbity: All-atom structure validation for macromolecular crystallography. Acta Crystallogr D Biol Crystallogr 66: 12-21.

Clouse KN, Ferguson SB, Schüpbach T. 2008. Squid, Cup, and PABP55B function together to regulate gurken translation in Drosophila. Dev Biol 313: 713-724.

Cohen N, Sharma M, Kentsis A, Perez JM, Strudwick S, Borden KL. 2001. PML RING suppresses oncogenic transformation by reducing the affinity of eIF4E for mRNA. EMBO $J$ 20: $4547-$ 4559.

Curry S, Kotik-Kogan O, Conte MR, Brick P. 2009. Getting to the end of RNA: Structural analysis of protein recognition of $5^{\prime}$ and $3^{\prime}$ termini. Biochim Biophys Acta 1789: 653-666.

Dostie J, Lejbkowicz F, Sonenberg N. 2000. Nuclear eukaryotic initiation factor $4 \mathrm{E}$ (eIF4E) colocalizes with splicing factors in speckles. J Cell Biol 148: 239-247.

Emsley P, Cowtan K. 2004. Coot: Model-building tools for molecular graphics. Acta Crystallogr D Biol Crystallogr 60: 21262132.

Filardo P, Ephrussi A. 2003. Bruno regulates gurken during Drosophila oogenesis. Mech Dev 120: 289-297.

Gebauer F, Hentze MW. 2004. Molecular mechanisms of translational control. Nat Rev Mol Cell Biol 5: 827-835.

Gingras AC, Gygi SP, Raught B, Polakiewicz RD, Abraham RT, Hoekstra MF, Aebersold R, Sonenberg N. 1999. Regulation of 4E-BP1 phosphorylation: A novel two-step mechanism. Genes Dev 13: 1422-1437.

Gross JD, Moerke NJ, von der Haar T, Lugovskoy AA, Sachs AB, McCarthy JEG, Wagner G. 2003. Ribosome loading onto the mRNA cap is driven by conformational coupling between eIF4G and eIF4E. Cell 115: 739-750.

Haghighat A, Sonenberg N. 1997. eIF4G dramatically enhances the binding of eIF4E to the mRNA 5' -cap structure. J Biol Chem 272: 21677-21680.

Haghighat A, Mader S, Pause A, Sonenberg N. 1995. Repression of cap-dependent translation by $4 \mathrm{E}-$ binding protein 1: Competition with p220 for binding to eukaryotic initiation factor-4E. EMBO J 14: 5701-5709.

Hershey PE, McWhirter SM, Gross JD, Wagner G, Alber T, Sachs AB. 1999. The Cap-binding protein eIF4E promotes folding of a functional domain of yeast translation initiation factor eIF4G1. J Biol Chem 274: 21297-21304

Igreja C, Izaurralde E. 2011. CUP promotes deadenylation and inhibits decapping of mRNA targets. Genes Dev 25: 1955-1967.

Jackson RJ, Hellen CUT, Pestova TV. 2010. The mechanism of eukaryotic translation initiation and principles of its regulation. Nat Rev Mol Cell Biol 11: 113-127.

Kabsch W. 1993. Automatic processing of rotation diffraction data from crystals of initially unknown symmetry and cell constants. J Appl Cryst 26: 795-800.

Keyes LN, Spradling AC. 1997. The Drosophila gene $f_{s}(2)$ cup interacts with $o t u$ to define a cytoplasmic pathway required for the structure and function of germ-line chromosomes. Development 124: 1419-1431.

Kim-Ha J, Kerr K, Macdonald PM. 1995. Translational regulation of oskar mRNA by bruno, an ovarian RNA-binding protein, is essential. Cell 81: 403-412.

Lin TA, Kong X, Haystead TA, Pause A, Belsham G, Sonenberg N, Lawrence JC. 1994. PHAS-I as a link between mitogen-activated protein kinase and translation initiation. Science 266: $653-656$.
Liu W, Jankowska-Anyszka M, Piecyk K, Dickson L, Wallace A, Niedzwiecka A, Stepinski J, Stolarski R, Darzynkiewicz E, Kieft J, et al. 2011. Structural basis for nematode eIF4E binding an $\mathrm{m}^{2,2,7} \mathrm{G}$-Cap and its implications for translation initiation. Nucleic Acids Res 39: 8820-8832.

Mader S, Lee H, Pause A, Sonenberg N. 1995. The translation initiation factor eIF-4E binds to a common motif shared by the translation factor eIF- $4 \gamma$ and the translational repressors 4E-binding proteins. Mol Cell Biol 15: 4990-4997.

Marcotrigiano J, Gingras AC, Sonenberg N, Burley SK. 1997. Cocrystal structure of the messenger RNA $5^{\prime}$ cap-binding protein (eIF4E) bound to 7-methyl-GDP. Cell 89: 951-961.

Marcotrigiano J, Gingras AC, Sonenberg N, Burley SK. 1999. Capdependent translation initiation in eukaryotes is regulated by a molecular mimic of eIF4G. Mol Cell 3: 707-716.

Matsuo H, Li H, McGuire AM, Fletcher CM, Gingras AC, Sonenberg N, Wagner G. 1997. Structure of translation factor eIF4E bound to $\mathrm{m}^{7} \mathrm{GDP}$ and interaction with 4E-binding protein. Nat Struct Biol 4: $717-724$.

McCoy A, Grosse-Kunstleve R, Adams P, Winn M, Storoni L, Read R. 2007. Phaser crystallographic software. J Appl Crystallogr 40: 658674.

McCubbin WD, Edery I, Altmann M, Sonenberg N, Kay CM. 1988. Circular dichroism and fluorescence studies on protein synthesis initiation factor eIF-4E and two mutant forms from the yeast Saccharomyces cerevisiae. J Biol Chem 263: 17663-17671.

McGuire AM, Matsuo H, Wagner G. 1998. Internal and overall motions of the translation factor eIF4E: Cap binding and insertion in a CHAPS detergent micelle. J Biomol NMR 12: 73-88.

Mizuno A, In Y, Fujita Y, Abiko F, Miyagawa H, Kitamura K, Tomoo $\mathrm{K}$, Ishida T. 2008. Importance of C-terminal flexible region of $4 \mathrm{E}-$ binding protein in binding with eukaryotic initiation factor $4 \mathrm{E}$. FEBS Lett 582: 3439-3444.

Monzingo AF, Dhaliwal S, Dutt-Chaudhuri A, Lyon A, Sadow JH, Hoffman DW, Robertus JD, Browning KS. 2007. The structure of eukaryotic translation initiation factor- $4 \mathrm{E}$ from wheat reveals a novel disulfide bond. Plant Physiol 143: 1504-1518.

Nakamura A, Sato K, Hanyu-Nakamura K. 2004. Drosophila Cup is an eIF4E binding protein that associates with Bruno and regulates oskar mRNA translation in oogenesis. Dev Cell 6: 69-78.

Nelson MR, Leidal AM, Smibert CA. 2004. Drosophila Cup is an eIF4E-binding protein that functions in Smaug-mediated translational repression. $E M B O J$ 23: 150-159.

Niedzwiecka A, Marcotrigiano J, Stepinski J, Jankowska-Anyszka M, Wyslouch-Cieszynska A, Dadlez M, Gingras A-C, Mak P, Darzynkiewicz E, Sonenberg N, et al. 2002a. Biophysical studies of eIF4E cap-binding protein: Recognition of mRNA 5' cap structure and synthetic fragments of eIF4G and 4E-BP1 proteins. $J$ Mol Biol 319: 615-635.

Niedzwiecka A, Stepinski J, Darzynkiewicz E, Sonenberg N, Stolarski R. 2002b. Positive heat capacity change upon specific binding of translation initiation factor eIF4E to mRNA 5' Cap. Biochemistry 41: $12140-12148$

Niesen FH, Berglund H, Vedadi M. 2007. The use of differential scanning fluorimetry to detect ligand interactions that promote protein stability. Nat Protoc 2: 2212-2221.

Niessing D, Blanke S, Jäckle H. 2002. Bicoid associates with the 5' cap-bound complex of caudal mRNA and represses translation. Genes Dev 16: 2576-2582.

Norvell A, Kelley RL, Wehr K, Schüpbach T. 1999. Specific isoforms of squid, a Drosophila hnRNP, perform distinct roles in Gurken localization during oogenesis. Genes Dev 13: 864-876.

Paku KS, Umenaga Y, Usui T, Fukuyo A, Mizuno A, In Y, Ishida T, Tomoo K. 2011. A conserved motif within the flexible C-terminus of the translational regulator $4 \mathrm{E}-\mathrm{BP}$ is required for tight binding to the mRNA cap-binding protein eIF4E. Biochem J 441: 237245.

Pause A, Belsham GJ, Gingras AC, Donzé O, Lin TA, Lawrence JC, Sonenberg N. 1994. Insulin-dependent stimulation of protein 
synthesis by phosphorylation of a regulator of $5^{\prime}$-cap function. Nature 371: 762-767.

Ptushkina M, von der Haar T, Vasilescu S, Frank R, Birkenhäger R, McCarthy JE. 1998. Cooperative modulation by eIF4G of eIF4Ebinding to the mRNA $5^{\prime}$ cap in yeast involves a site partially shared by p20. EMBO J 17: 4798-4808.

Ptushkina M, von der Haar T, Karim MM, Hughes JM, McCarthy JE. 1999. Repressor binding to a dorsal regulatory site traps human eIF4E in a high cap-affinity state. EMBO J 18: 4068-4075.

Reichmann D, Cohen M, Abramovich R, Dym O, Lim D, Strynadka NCJ, Schreiber G. 2007. Binding hot spots in the TEM1-BLIP interface in light of its modular architecture. J Mol Biol 365: 663-679.

Rosettani P, Knapp S, Vismara M-G, Rusconi L, Cameron AD. 2007. Structures of the human eIF4E homologous protein, h4EHP, in its $\mathrm{m}^{7}$ GTP-bound and unliganded forms. J Mol Biol 368: 691-705.

Scheper GC, van Kollenburg B, Hu J, Luo Y, Goss DJ, Proud CG. 2002. Phosphorylation of eukaryotic initiation factor $4 \mathrm{E}$ markedly reduces its affinity for capped mRNA. J Biol Chem 277: 3303-3309.

Schüpbach T, Wieschaus E. 1991. Female sterile mutations on the second chromosome of Drosophila melanogaster. II. Mutations blocking oogenesis or altering egg morphology. Genetics 129: 1119-1136.

Siddiqui N, Tempel W, Nedyalkova L, Volpon L, Wernimont AK, Osborne MJ, Park H-W, Borden KLB. 2012. Structural insights into the allosteric effects of 4EBP1 on the eukaryotic translation initiation factor eIF4E. J Mol Biol 415: 781-792.

Sonenberg N, Hinnebusch AG. 2009. Regulation of translation initiation in eukaryotes: Mechanisms and biological targets. Cell 136: 731-745.

Studier FW. 2005. Protein production by auto-induction in high density shaking cultures. Protein Expr Purif 41: 207-234.

Tomoo K, Shen X, Okabe K, Nozoe Y, Fukuhara S, Morino S, Sasaki M, Taniguchi T, Miyagawa H, Kitamura K, et al. 2003. Structural features of human initiation factor $4 \mathrm{E}$, studied by X-ray crystal analyses and molecular dynamics simulations. J Mol Biol 328: 365-383.

Tomoo K, Matsushita Y, Fujisaki H, Abiko F, Shen X, Taniguchi T, Miyagawa H, Kitamura K, Miura K-i, Ishida T. 2005. Structural basis for mRNA cap-binding regulation of eukaryotic initiation factor $4 \mathrm{E}$ by $4 \mathrm{E}$-binding protein, studied by spectroscopic, X-ray crystal structural, and molecular dynamics simulation methods. Biochim Biophys Acta 1753: 191-208.
Topisirovic I, Svitkin YV, Sonenberg N, Shatkin AJ. 2011. Cap and cap-binding proteins in the control of gene expression. Wiley Interdiscip Rev RNA 2: 277-298.

Vardy L, Orr-Weaver TL. 2007. Regulating translation of maternal messages: Multiple repression mechanisms. Trends Cell Biol 17: 547-554.

Verrotti AC, Wharton RP. 2000. Nanos interacts with Cup in the female germline of Drosophila. Development 127: 5225-5232.

Volpon L, Osborne MJ, Topisirovic I, Siddiqui N, Borden KLB. 2006. Cap-free structure of eIF4E suggests a basis for conformational regulation by its ligands. EMBO J 25: 5138-5149.

Volpon L, Osborne MJ, Capul AA, de la Torre JC, Borden KLB. 2010. Structural characterization of the Z RING-eIF4E complex reveals a distinct mode of control for eIF4E. Proc Natl Acad Sci 107: 5441-5446.

von der Haar T, Ball PD, McCarthy JE. 2000. Stabilization of eukaryotic initiation factor $4 \mathrm{E}$ binding to the mRNA $5^{\prime}$-Cap by domains of eIF4G. J Biol Chem 275: 30551-30555.

von der Haar T, Gross JD, Wagner G, McCarthy JEG. 2004. The mRNA cap-binding protein eIF4E in post-transcriptional gene expression. Nat Struct Mol Biol 11: 503-511.

von der Haar T, Oku Y, Ptushkina M, Moerke N, Wagner G, Gross JD, McCarthy JEG. 2006. Folding transitions during assembly of the eukaryotic mRNA cap-binding complex. J Mol Biol 356: 982-992.

Webster PJ, Liang L, Berg CA, Lasko P, Macdonald PM. 1997. Translational repressor bruno plays multiple roles in development and is widely conserved. Genes Dev 11: 2510-2521.

Wilhelm JE, Hilton M, Amos Q, Henzel WJ. 2003. Cup is an eIF4E binding protein required for both the translational repression of oskar and the recruitment of Barentsz. J Cell Biol 163: 1197-1204.

Yanagiya A, Svitkin YV, Shibata S, Mikami S, Imataka H, Sonenberg N. 2009. Requirement of RNA binding of mammalian eukaryotic translation initiation factor 4GI (eIF4GI) for efficient interaction of eIF4E with the mRNA cap. Mol Cell Biol 29: 1661-1669.

Zappavigna V, Piccioni F, Villaescusa JC, Verrotti AC. 2004. Cup is a nucleocytoplasmic shuttling protein that interacts with the eukaryotic translation initiation factor $4 \mathrm{E}$ to modulate Drosophila ovary development. Proc Natl Acad Sci 101: 14800-14805.

Zhai B, Villén J, Beausoleil SA, Mintseris J, Gygi SP. 2008. Phosphoproteome analysis of Drosophila melanogaster embryos. J Proteome Res 7: 1675-1682. 

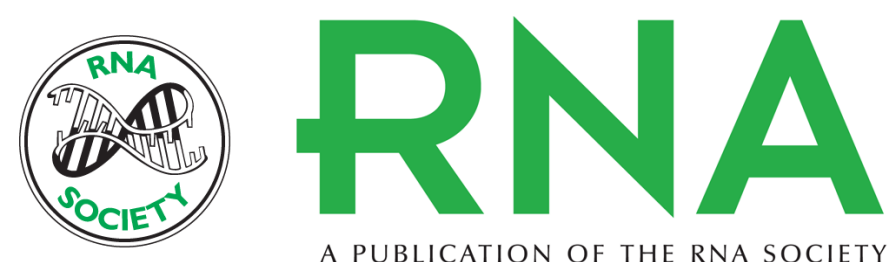

A PUBLICATION OF THE RNA SOCIETY

\section{Crystal structure of a minimal elF4E-Cup complex reveals a general mechanism of elF4E regulation in translational repression}

Kerstin Kinkelin, Katharina Veith, Marlene Grünwald, et al.

RNA 2012 18: 1624-1634 originally published online July 25, 2012

Access the most recent version at doi:10.1261/rna.033639.112

Supplemental
Material http://rnajournal.cshlp.org/content/suppl/2012/07/10/rna.033639.112.DC1

References This article cites 67 articles, 24 of which can be accessed free at: http://rnajournal.cshlp.org/content/18/9/1624.full.html\#ref-list-1

License

Email Alerting Receive free email alerts when new articles cite this article - sign up in the box at the Service top right corner of the article or click here. 